\title{
On strong inferences and irreproducibility in reproductive medicine
}

\author{
David F. Albertini ${ }^{1}$
}

Published online: 22 May 2017

(C) Springer Science+Business Media New York 2017

The aim of an argument or discussion should not be victory, but progress.

Joseph Joubert, essayist (1754-1824)

Imagine measuring progress in science in 1964 if you were at the mercy of the tools, validated and proven in basic or applied medical research of the day, that would be adopted to test your favorite hypothesis. The forerunners of today's technology were at best rudimentary when viewed through a seasoned lens five decades hence. With methods and data collection so time consuming and tedious, it would have been more appropriate in retrospect to refer to such times as the era of "small data." And even in those primitive days of what would become the medical research enterprise of today, the perceptions of some were remarkably prescient and extraordinarily respectful of what their data could, should, or would mean.

Such was the theme of Pratt's premonition earmarked for future generations, a cautionary tale that holds as much relevance to the discipline of reproductive medicine today as it does for many other research disciplines, medical or otherwise [1]. Consider the opening paragraph of his message, again being mindful of a frontier yet to have been discovered:

Scientists these days tend to keep up a polite fiction that all science is equal. Except for the work of the misguided opponent whose arguments we happen to be refuting at the time, we speak as though every scientist's field and methods of study are as good as every other scientist's, and perhaps a little

David F. Albertini

dalbertini@thechr.com

1 The Center for Human Reproduction, New York, NY, USA better. This keeps us all cordial when it comes to recommending each other for government grants.

Anyone who has served on a government-funded peer review panel knows well that being cordial when it comes to your competition (whether real or perceived) is possibly the last quality funding agencies would be looking for in seeking your professional opinion on a grant proposal. Moreover, Pratt's premise, if applied to contemporary research in reproductive medicine whether here in the USA or abroad, would acknowledge his definition of "strong inference" as the point at which rapid progress in technology and method is coupled to effective inductive inference (my paraphrasing). Or does it?

Science at present is inundated with data, supercomputers, biological samples of experimentally tractable or intractable value, and commercial drivers - all of which were absent in 1964. Investigators of old carved careers based on submitting grants that made them the beneficiaries of what would become, and remains today, the largest and most generous of funding agencies in the biomedical enterprise, known as the National Institutes of Health (NIH). Competitive attitudes to acquire funding certainly remain, but the goal currently is about making money under the occasional pretense of scholarship.

Very recently, ESHRE published its May 2017 Focus on Reproduction providing their readership with updates of all kinds, but two pieces truly stand out in my estimation for their timeliness and relevance to the direction human ARTs is taking (www.eshre.eu/Login/MyESHRE/Newsletters.aspx?ec as=B23D91A3D79D493184307FE9BF1F6394).

The first is coverage of the "Best of...meeting" jointly sponsored by ESHRE and ASRM and summarized in sufficient detail so as to inform we members not fortunate enough to have been amongst those in attendance. Here, the collective message is recognizing that differences of opinion rest somewhere in the middle of debates shaped around the manifold 
controversies inspiring (eventually and hopefully for the eternal optimist) consensus regarding the practice of ARTs - at least on two borders of the Atlantic Ocean. This nexus for the future will be greeted most favorably by ART consumers should the spirit of cooperation in such a format continue to accept the difference between strong inference and the rush to judgment evidenced by the rampant introduction of new methodologies.

And speaking of consumers, Focus also takes a close look at the adoption and utility of preimplantation genetic screening (PGS) and what needs to happen before coverage is guaranteed for any and all patients who would benefit from its implementation on select or widespread populations. Again, and in contradistinction to ESHRE's constituencies, this has become a moot point in the USA with the successful harnessing of the power of NGS and the apparent mismeasure of mosaicism fully resolved [2]. Both the incidence and applicability of PGS over a broad range of patients [3] will increase market value for the various companies fortunate to have provided this testing to infertility centers and their clients [4]. Here, at JARG, we applaud the efforts of ESHRE in this and so many other endeavors in the field of reproductive medicine where the boundaries imposed by inferences, whether strong or weak, bear the signature of careful, thoughtful, and thorough scrutiny of the methodology and utility of this and other "adjuncts" being introduced into the human ART marketplace.

Valued in any scientific discipline as the cornerstone of discovery is the matter of reproducibility. And no surprise to most, there has been an uproar since the finding that throughout many scientific fields of study, reproducibility in the published literature has emerged as a liability in thwarting the credibility and utility of so-called new knowledge [5]. In reproductive medicine, our reliance on outcome reporting is slowly evolving - the good news - but here too, as much as corralling bias is a recognized and very real concern especially on the pathway to meta-analyses, progress has not become our most important product as noted in other disciplines by Ioannidis and his colleagues [6].

With these guiding principles and worrisome complications that often escape detection by we practitioners (and our patients) as they race to bear children through ARTs comes a sense of responsibility to maintain a focus and commitment to furthering the knowledge base upon which a credible course to the diagnosis and treatment of infertility will be achieved well into the future. That JARG will maintain the standards of contemporary science in seeking this end rests firmly in the hands of our Editorial Board and the many reviewers and contributors who drive us as scholars instead of entrepreneurs.

\section{References}

1. Platt JR. Strong inference: certain systematic methods of scientific thinking may produce much more rapid progress than others. Science. 1964;146(3642):347-53.

2. Munne S, Wells D. Detection of mosaicism at blastocyst stage with the use of high-resolution next-generation sequencing. Fertil Steril. 2017;107(5).

3. Capalbo A, Rienzi L. Mosaicism between trophectoderm and inner cell mass. Fertil Steril. 2017;107(5):1098-106.

4. Simon C. Introduction: to transfer or not transfer...a mosaic embryo, that is the question. Fertil Steril. 2017;107(5):1083-4.

5. Ioannidis JPA. The reproducibility wars: successful, unsuccessful, uninterpretable, exact, conceptual, triangulated, contested replication. Clin Chem. 2017;63(5):943-5.

6. Ioannidis JP, Caplan AL, Dal-Re R. Outcome reporting bias in clinical trials: why monitoring matters. BMJ. 2017;356:j408. 